and has not since experienced any return of his complaint, although it is eight months since he left off taking medicine. He says that he never remembers having been so well as he is at the present time.

\section{PLACENTAR PRESENTATIONS.}

\section{To the Editor of The LANCET.}

Sir:-In the excellent practical lecture of Dr. Ingleby on Placentar Presentations, published in the last LANCET, the following sentences occur, on which $I$ beg leave to make a few observations. "But supposing the uterine orifice to have been too rigid to have yielded to the hand, could the plug have been safely employed whilst waiting for the desired relaxation? The risk of blood accumulating internally in large quantities, constitutes the only objection which can attend its employment."

Some time since $I$ was requested by a medical friend to attend for him in a case of labour. The patient resided about fonr miles from his house, and was stated by her husband to have had a discharge of blood just before he left. I attended immediately, and on reaching the house, found that the female, a robust young woman in labour with her first child, had been perfectly well till two hours hefore, when, on moving a tub which contained some things she had been washing, she felt what she called a " cramp in her stomach," and a few minutes afterwards some blood passed by the vagina. This gave me the idea of the separation of a part of the placesta, but on making an examination $I$ found the os uteri about the size of a shilling, its edges thin, but hard, like a piece of whipcord, and the placenta lying over its whole circumference. By examining the cervix uteri, also, I had very little doubt that the principal part of it was covered by the attached placenta. While I was examining, another pain and $a$ fresh discharge of blood took place, and being unwilling to incur the wbole responsibility of the case, I sent off for my friend. The hæmorrhage continued to increase, and the os uteri being so rigid that turning was out of the question, it struck me that if $I$ could prevent the flow of blood by the vagina (the placenta being attached all round the os uteri, would act as a plug, and prevent any bleeding into the cavity of the uterus), $I$ could safely wait for dilatation of the os uteri. I accordingly filled the whole of the upper part of the vagina with smail pieces of soft linen, and then plugged the os externum with a pocket handkerchief. My friend arrived soon after this, and perfectly agreed in the propriety of my proceedings. We both waited to watch the case, and found that though the pains regularby recurred, no hæmorrhage was taking place. Things continued in this state for about six hours, when all at once the handkerchief was forced out, and a great gush of blood followed it. The surgeon passed his hand immediately into the vagina, but on eadeavouring to enter the os uteri, the woman complained so loudly that it veas determined, as my hand was much smaller than his, that I should attempt immediate delivery.

I found the os nteri about as large as a crown piece, and covered by the placenta. I was passing my hand through it with the purpose of separating more of the placenta, rupturing the membranes, and seizing the feet; when, just as $I$ had reached the edge of the placenta, the membranes gave way, and a powerful contraction came on, which expelled my hand into the vagina, with a large quantity of blood and liquor amnii. I repassed it as soon as the contraction ceased, seized one knee, and, the external parts being relaxed, soon completed the delivery. The placenta immediately followed the birth of the head of the child. The woman suffered for some days from weakness and headach, but was soon quite well, and employed in her household affiars.

The only observation I have to make is, that $I$ should pursue the same practice in any similar case which might occur to me, without the slightest apprehension of internal hæmorrhage. I am, Sir, respectfully yours,

$$
\text { London, March 23, } 1840 .
$$

$$
\text { T. S. W ELLS. }
$$

\section{THE VACCINATION BILL.}

\section{To the Editor of The LAncet.}

Sir :-The Bill which has just passed the House of Lords, entitled "An Act to extend the Practice of Vaccination," dies not, in my humble opinion, advance that much-desired object in the least ; it merely gives the Guardians authority "to contract with the Medical Officers of their several Unions respectively for the vaccination of all children who may be brought to them for that purpose ;" a power they always possessed, and generally acted upon; nor is it the want of means which causes the poor to neglect this blessing, for they have innumerable public and private facilities for obtaining gratuitous vaccination, and, therefore, if the law is to be made effectual, a compul. sory clause must be introduced, inflicting a fine, in default of vaccination before a certain age, say three months.

I would also suggest an alteration in the first clause of the Bill, viz.-instead of the words " all children who may be brought to them, \&c.,"I would say, all persons, as it would often be desirable to vaccinate adults, as well as children.

\section{2}


Your able attention to these points, when the Bill comes before the House of Commons, will, I am sure, be duly appreciated by the public and the profession. I am, Sir, your obedient servant,

\section{London-rond, Southwark,}

R. L. HOOPER.

March 25, 1840.

** We await the appearance of the Bill in the House of Commons.-ED. L.

\section{TH E LA N C E T.}

\section{London, Saturday, March 28, 1840.}

The Poor-Law Commissioners have just presented "A Report to the Marquis of Nor" MANBY on the Continuance of the Poor.Law "Commission, and on some future Amendments "of the Laws relating to the Relief of the "Poor." Medical Relief is among the sub. jects examined, and at a future time it may be necessary to discuss in this Journal the question of the continuance of the PoorLaw Commission; but we shall, at present, only offer a remark or two upon the plan of Medical Relief proposed in the Report.

The Report is understood to have been written by Mr. G. C. Lewis; and we are glad to be able to state that the section on Medical Relief is carefully drawn up, and evinces more fairness and humanity, than the paragraphs in the early Reports that called down general animadversion. The Commissioners appear to have learnt something from the Report of the Parliamentary Committee; and we may assure them that the Medical Profesion are quite willing to forget their misdeeds, their blind zeal, and their galling tyranny, if there be a prospect of the past evils never being renewed.

The Commissioners begin by observing that, "In the Statute of Elizabetr no allu"sion to Medical Relief is to be found, and " in the subsequent Acts of Parliament, relat"ing to the Poor, the Legislature has been "entirely silent on the subject." The reason of this is explained by the History of the Medical Profession. In the time of Elizabeth the Poor could have no Medical
Advice, as the number of educated Practitioners was insufficient to supply the demands of the rich and the middle classes. The grocers were the druggists and apothecaries of the age.

Gale stated that in $\mathbf{1 5 6 6}$ there were not $\mathbf{3 4}$ surgeons of the whole company of Englishmen, and that the greater part of the 34 were in the service of noblemen. In 1618, the number of physicians in the London District was 34 ; and at that time the Annual Deaths within the Bills of Mortality alone, amounted to 15,000. To 900 sick persons there was one Physician; at present there is in the Metropolis at least one Practitioner to 54 persons constantly sick. In the time of ElrzABETH the great mass of the population trusted to magic, miracles, mountebanks, old women, "carpenters, pewterers, braziers, soap-ballsellers, pulters, hostellers, and painters." (CAlus.) The Acts of Parliament extend the list of irregular practitioners, and de. nounce them in unmeasured terms. It is quite evident, however, that the individuals denounced were the established practitioners of the age; and that the project for their suppression was the only novelty. Ladies and gentlemen in the country had their recipes, and in fits of benevolence administered herb-teas and bad drugs to the destitute; but the legal provision of Medical Relief for paupers, in the age of Elizabeth, or in any part of the 16th or $17^{\text {th }}$ century, was out of the question.

The terrific plagues of those centuries are recorded in our history, and mark too well the destitution of the Poor, the ignorance of the laws of life, and the want of medical knowledge which prevailed.

The Poor-Law Commissioners have fre. quently adverted to the fact, that the early Acts of Parliament contained no provision for the Medical Relief of the Poor, or for the preservation of their Health; but that is no reason why the Poor should be neglected now, when medicine has made so much progress, and may render them effectual servico. To the observations on the extent of the Medical Districts we can offer no objections : 